\title{
Research
}

Stefan Walen, Roger AMJ Damoiseaux, Steven M Uil and Jan WK van den Berg

\section{Diagnostic delay of pulmonary embolism in primary and secondary care:}

\author{
a retrospective cohort study
}

\begin{abstract}
\section{Background}

Delayed diagnosis of pulmonary embolism (PE) is common because symptoms can be non-specific. The few studies that have investigated diagnostic delay have not taken into account the role of primary care physicians in the diagnostic process.

Aim

To document and quantify the stages of diagnostic delay of PE and to identify clinical factors associated with this delay.

\section{Design and setting}

A retrospective cohort study conducted in

Zwolle and its surroundings in the Netherlands.

\section{Method}

Primary and secondary care records of all patients diagnosed with PE between January 2008 and December 2009 were reviewed for dates of symptom onset, date of presentation and diagnosis, and for clinical findings. Relationships between delay and clinical parameters were tested using multivariate regression analysis.

\section{Results}

The 261 patients enrolled in the study had an average total delay of 8.6 days. Patient delay ( 4.2 days average) and delay in primary care ( 3.9 days) were the major contributors to this delay. Chest pain lodds ratio [OR] 0.51 $95 \%$ confidence interval $[\mathrm{Cl}]=0.28$ to 0.92 , $P=0.03$ ) and symptoms of deep venous thrombosis (calf pain) (OR 0.49, 95\% Cl = 0.24 to $0.98, P=0.05$ ) were associated with an early diagnosis. Patient delay was shorter in patients with chest pain lOR $0.49,95 \% \mathrm{Cl}=0.25$ to 0.95 , $P=0.03$ ) and longer in patients with dyspnoea (OR $2.95,95 \% \mathrm{Cl}=0.99$ to $8.85, P=0.05$ ). In primary care, chest pain $[\mathrm{OR} 0.37,95 \% \mathrm{Cl}=0.17$ lethal disorder, requiring timely and adequate treatment. The mortality rate is high, with $7.7-15 \%$ of patients dying within 3 months. ${ }^{1-3}$ However, because signs and symptoms are non-specific, timely recognition of acute $\mathrm{PE}$ remains a great challenge and delayed diagnosis is common. In a recent Turkish study up to $30 \%$ of patients diagnosed with PE had a delay longer than 7 days. ${ }^{4}$ The diagnostic delay of pulmonary embolism has been the subject of study and varied from 4.8 to 8.4 days. ${ }^{4-6}$ However, few studies have looked into the various stages of total diagnostic delay for PE. In 1995, Andersen et al proposed a model dividing total diagnostic delay into patient delay (further divided into appraisal delay, illness delay, behavioural delay, and scheduling delay) and treatment delay, focusing mainly on the prediagnostic period. ${ }^{7}$ In the following years several adaptations were proposed, focusing more on primary and secondary care intervals. ${ }^{8.9}$ Consensus about the definitions of the stages of delay is still lacking, although a recent statement was published to provide an internationally accepted framework. ${ }^{10}$

In particular, the role of the GP in the diagnostic process is interesting. In countries like the Netherlands, where primary care has a gatekeeping function
\end{abstract} to $0.84, P=0.02$ ) and rales (OR $0.22,95 \% \mathrm{Cl}=0.06$ to $0.83, P=0.03$ ) were associated with an early referral, whereas comorbidity led to a delayed referral.

\section{Conclusion}

This study shows that the diagnostic delay of PE is substantial, especially patient delay and delay in primary care. There is room to reduce this delay by increasing the awareness of both patients and GPs. Further research is needed on clinical factors that raise suspicion of PE in primary care.

\section{Keywords}

comorbidity; diagnostic delay; primary care

pulmonary embolism; secondary care.

\section{INTRODUCTION}

Pulmonary embolism (PE) is a potentially

S Walen, MD, resident pulmonologist; SM Uil MSc, clinical epidemiologist; JWK van den Berg, MD, PhD, pulmonologist, Department of Pulmonology, Isala, Zwolle, Netherlands. RAMJ Damoiseaux, GP, MD, PhD, General Practice De Hof van Blom, Hattem, the Netherlands, and professor of education and evidence-based medicine in general practice, Julius Centre for Health Sciences and Primary Care, University Medical Centre Utrecht, Utrecht, the Netherlands. Address for correspondence

Stefan Walen, Department of Pulmonology, for secondary care, many patients with PE will be seen by their GP first. Therefore, the decisions made in primary care are essential in the diagnostic process. Recently it was shown that PE can be safely excluded in primary care when there is a combination of a low clinical probability (that is, a Wells score of four points or less) and a negative point-ofcare D-dimer. ${ }^{11}$ However, before using any diagnostic algorithm there must first be a suspicion of PE. Barais et al described this first step in a qualitative study where they determined that, among other factors, 'gut feeling' played an important role in raising suspicion for PE. ${ }^{12}$ Nonetheless, pulmonary embolism appears to be one of the most missed diagnoses in primary care. $^{13}$

The primary objective of this study was to document and quantify the various stages of diagnostic delay of pulmonary embolism in patients referred to hospital from primary care. It also aimed to identify clinical variables associated with diagnostic delay.

\section{METHOD}

\section{Study design}

This was a retrospective cohort study conducted at Isala, a large teaching hospital in Zwolle, in the Netherlands.

\section{Study setting and population}

The authors searched hospital electronic

Isala, Dokter van Heesweg 2, 8025 AB, Zwolle, Netherlands.

E-mail: s.walendisala.nl

Submitted: 2 September 2015; Editor's response: 20 November 2015; final acceptance: 24 January 2016.

\section{CBritish Journal of General Practice}

This is the full-length article (published online 26 Apr 2016) of an abridged version published in print. Cite this article as: Br J Gen Pract 2016; DOI: 10.3399/bjgp16X685201 


\section{How this fits in}

Little is known about the various stages of diagnostic delay of pulmonary embolism (PE). This study shows that delay in primary care contributes significantly to total delay. Chest pain and rales were associated with an early referral whereas comorbidity led to a delayed referral. Further research is needed on clinical factors that raise suspicion of $\mathrm{PE}$ to reduce this delay.

clinical records to identify all patients diagnosed with pulmonary embolism between January 2008 and December 2009 in the Isala clinics, in Zwolle, the Netherlands. Patients had to be $\geq 18$ years of age at the time of diagnosis. All patients who were not referred from primary care were excluded. These consisted of patients who were referred from another hospital or outpatient clinic, patients who developed an embolism during their stay at the hospital (for example, after surgery), or patients in whom an embolism was seen as an incidental finding on a spiral computed tomography (CT). In addition, patients who were diagnosed without radiological confirmation were excluded. Data of eligible patients were entered into a database.

\section{Outcomes}

The primary outcome of this study was the diagnostic delay in days. This was subdivided into patient delay, defined as the number of days between symptom onset and the first presentation at primary care; delay in primary care, defined as the number of

Figure 1. Flowchart of patient selection. $P E=$ pulmonary embolism days between first presentation at primary

\section{Patients diagnosed with PE $(n=391)$}

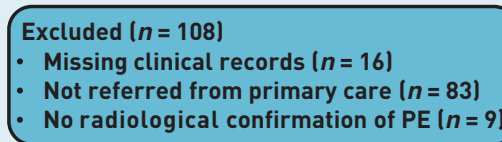

No radiological confirmation of PE $(n=9)$

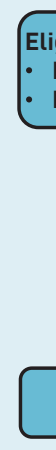

After retrieving primary care records for incomplete records $(n=121)$

- Successful, inclusion in study ( $n=99)$

Unsuccessful, exclusion from study $(n=22)$

Included for analysis $n=261$ care and referral; delay in secondary care defined as the number of days between first presentation at the hospital and diagnosis; and total diagnostic delay, defined as the number of days between symptom onset and the time of diagnosis. Secondary outcomes were the association between clinical variables and diagnostic delay, expressed as odds ratios.

\section{Data collection}

Patients' hospital records were reviewed for date of symptom onset, date of first presentation to primary care, date of first presentation to secondary care, and date of diagnosis. From this information, patient delay, delay in primary care, delay in secondary care, and total diagnostic delay were calculated. If delay was not described in days, but in weeks or months (for example, chest pain for 2 weeks), an estimate was made $(7$ days for a week, 28 , 30 , or 31 days for a month, depending on the specific month). Furthermore, clinical symptoms, signs, and risk factors were recorded. GPs were asked to obtain and supply any missing data from the primary care records.

\section{Data analysis}

Descriptive statistics were used for the analysis of baseline characteristics. The mean diagnostic delay was expressed in days +/- standard deviation. To test associations between clinical variables and delay, delay was dichotomised. Patient delay and delay in primary care were dichotomised with the following cut-off points: 0 to 5 days and $\geq 6$ days. The cut-off points for delay in secondary care were 0 to 2 days and $\geq 3$ days, and for total delay 0 to 6 days and $\geq 7$ days. Binary univariate logistic regression analysis was used to test the associations between variables and delay. Variables with a $P \leq 0.20$ were included in multivariate logistic regression analysis. A multivariate model was made using the Enter-method. To interpret results of multivariate analyses $P$-values $\leq 0.05$ were considered significant. Data analyses were performed using the Statistical Package for the Social Sciences (SPSS), version 17.0.

\section{RESULTS}

Between January 2008 and December 2009, 391 patients were diagnosed with pulmonary embolism in the Isala clinics. A total of 16 patients were excluded because their medical records were missing, 83 patients because they had not been referred from primary care, and nine patients because the diagnosis was made on 
Table 1. Patient characteristics for analysis of diagnostic delay in pulmonary embolism ( $N=261$ )

\begin{tabular}{lc} 
Patient characteristic & \\
\hline Sex, $n(\%)$ & $136(52.1)$ \\
Male & $125(47.9)$ \\
Female & $60.6(16.9 .19-94)$ \\
\hline Mean age, years (SD, range) & $12(4.6)$ \\
\hline Comorbidity, $n(\%)^{a}$ & $29(11.1)$ \\
Heart failure & $15(5.7)$ \\
AP/myocardial infarction & $11(4.2)$ \\
Rheumatoid arthritis & $21(8.0)$ \\
COPD & $8(3.1)$ \\
Asthma & \\
Depression
\end{tabular}

aSome patients were diagnosed with more than one condition. $A P=$ angina pectoris, here defined as typical chest pain, diagnosed by a cardiologist. $C O P D=$ chronic obstructive pulmonary disease. $S D=$ standard deviation .

clinical grounds (that is, without radiological confirmation). In 121 cases, data on delay or clinical symptoms were missing from the clinical records. For these patients, the authors requested that patients' GPs supply the missing information. As a result, records for 99 patients could be completed, leading to a total number of 261 patients for analysis (see Figure 1 for an outline of the study process). Table 1 and Table 2 show patient characteristics. Table 3 and Tables 5-7 show univariate analysis of the stages of diagnostic delay.

\section{Total diagnostic delay}

On average, patients were diagnosed $8.6+/-25.5$ days after symptom onset (median 3 days, range $0-346$ ). In total, 59 patients $(22.6 \%)$ were diagnosed with $\mathrm{PE}$ within a day of the onset of symptoms. Sixty-two patients (23.8\%) had a diagnostic delay of longer than a week and $16(6.1 \%)$ had a diagnostic delay of longer than a month. Multivariate analysis of clinical variables (Table 4) showed that calf pain lodds ratio [OR] 0.49, 95\% confidence interval $[\mathrm{Cl}]=0.24$ to $0.98, P=0.05$ ) and

\section{Table 2. Symptoms, signs, and risk factors for pulmonary embolism}

\begin{tabular}{|c|c|c|}
\hline & $n(N=261)$ & $\%$ \\
\hline \multicolumn{3}{|l|}{ Symptoms } \\
\hline Dyspnoea & 203 & 77.8 \\
\hline Chest pain & 156 & 59.8 \\
\hline Cough & 78 & 29.9 \\
\hline Haemoptysis & 9 & 3.4 \\
\hline Fever & 39 & 14.9 \\
\hline Calf pain & 73 & 28.0 \\
\hline \multicolumn{3}{|l|}{ Signs } \\
\hline Tachycardia ${ }^{a}$ & 76 & 29.5 \\
\hline Rales & 45 & 17.2 \\
\hline Decreased breath sounds & 26 & 10.0 \\
\hline Signs of DVT & 62 & 24.0 \\
\hline \multicolumn{3}{|l|}{ Risk factors } \\
\hline Known malignancy & 29 & 11.1 \\
\hline Previous DVT/PE & 48 & 18.4 \\
\hline Surgery/trauma or immobilisation ${ }^{b}$ & 30 & 11.5 \\
\hline Thrombophilia & 2 & 0.8 \\
\hline
\end{tabular}


Table 3. Total diagnostic delay: univariate analysis

\begin{tabular}{|c|c|c|c|}
\hline \multirow[b]{2}{*}{ Variable } & \multicolumn{3}{|c|}{ Late diagnosis $\geq 7$ days } \\
\hline & Odds ratio & $95 \% \mathrm{Cl}$ & $P$-value \\
\hline Age $>65$ years & 1.28 & 0.74 to 2.24 & 0.38 \\
\hline Male sex & 1.04 & 0.60 to 1.80 & 0.90 \\
\hline Comorbidity & 1.78 & 1.00 to 3.19 & $0.05^{\mathrm{a}}$ \\
\hline \multicolumn{4}{|l|}{ Symptoms } \\
\hline Dyspnoea & 2.62 & 1.17 to 5.87 & $0.02^{\mathrm{a}}$ \\
\hline Chest pain & 0.46 & 0.26 to 0.80 & $0.01^{a}$ \\
\hline Cough & 1.54 & 0.86 to 2.76 & $0.15^{\mathrm{a}}$ \\
\hline Haemoptysis ${ }^{b}$ & -- & - & \\
\hline Fever & 0.83 & 0.37 to 1.85 & 0.65 \\
\hline Calf pain & 0.53 & 0.27 to 1.05 & $0.07 a$ \\
\hline \multicolumn{4}{|l|}{ Signs } \\
\hline Tachycardiac $^{c}$ & 0.76 & 0.41 to 1.43 & 0.40 \\
\hline Rales & 0.67 & 0.30 to 1.47 & 0.31 \\
\hline Decreased breath sounds & 0.49 & 0.16 to 2.34 & $0.20^{a}$ \\
\hline Signs of DVT & 0.68 & 0.34 to 1.35 & 0.27 \\
\hline \multicolumn{4}{|l|}{ Risk factors } \\
\hline Previous DVT/PE & 1.07 & 0.53 to 4.37 & 0.86 \\
\hline Known malignancy & 0.72 & 0.28 to 1.84 & 0.49 \\
\hline Surgery or trauma & 0.53 & 0.20 to 1.45 & 0.22 \\
\hline Thrombophiliab & - & - & \\
\hline \multicolumn{4}{|c|}{$\begin{array}{l}{ }^{a} P \leq 0.20 \text {, therefore data included in multivariate logistic regression analysis (see Table } 4 \text { ). }{ }^{b} \text { No analysis due to lack of } \\
\text { data. }{ }^{c} \text { Tachycardia defined as heart rate }>100 \text { beats per minute. }{ }^{d} \text { Surgery or trauma in the previous } 4 \text { weeks. } \\
D V T=\text { deep venous thrombosis. } P E=\text { pulmonary embolism. }\end{array}$} \\
\hline
\end{tabular}

chest pain lOR $0.51,95 \% \mathrm{Cl}=0.28$ to 0.92 , $P=0.03$ ) were associated with an early diagnosis. Sex, age, and the presence of risk factors for PE were not significantly associated with a delay in diagnosis.

\section{Patient delay}

The average time between symptom onset and first presentation at primary care was $4.2+/-9.9$ days (median 1 day, range

\section{Table 4. Multivariate logistic regression analysis of clinical variables and delayed presentation (total diagnostic delay)}

\begin{tabular}{lccc} 
& \multicolumn{3}{c}{ Late diagnosis $\geq \mathbf{7}$ days } \\
\cline { 2 - 4 } Variable & Odds ratio & $\mathbf{9 5 \%} \mathbf{C l}$ & $\boldsymbol{P}$-value \\
\hline Chest pain & 0.51 & 0.28 to 0.92 & $0.03^{\mathrm{a}}$ \\
Calf pain & 0.49 & 0.24 to 0.98 & $0.05^{\mathrm{a}}$ \\
Dyspnoea & 2.21 & 0.95 to 5.15 & 0.07 \\
Comorbidity & 1.48 & 0.80 to 2.74 & 0.21 \\
Decreased breath sounds & 0.49 & 0.16 to 1.53 & 0.22 \\
Cough & 1.33 & 0.71 to 2.48 & 0.38 \\
\hline
\end{tabular}

a Statistically significant.
0-122), with 35 patients (13.4\%) waiting longer than a week before consulting their physician and five (1.9\%) waiting longer than a month. Multivariate analysis of the relationship between clinical variables and patient delay showed that there was a borderline association between dyspnoea and a longer delay $\operatorname{lOR} 2.95,95 \% \mathrm{Cl}=0.99$ to $8.85, P=0.05)$. Chest pain was significantly associated with earlier presentation (OR $0.49,95 \% \mathrm{Cl}=0.25$ to $0.95, P=0.03$ ).

\section{Delay in primary care}

The average time between first consultation and referral to secondary care was $3.9+/-20.1$ days (median 1 day, range $0-300$ ). Seventy-five per cent of patients were referred within 1 day but the remaining $25 \%$ had an average delay of 15.7 days. Multivariate analysis of the relationship between clinical variables and delay in primary care showed that comorbidity led to a longer delay IOR 3.01, $95 \% \mathrm{Cl}=1.36$ to $6.64, P=0.011$. The presence of chest pain was associated with an early referral (OR $0.37,95 \% \mathrm{Cl}=0.17$ to $0.84, P=0.02$ ) as was the finding of rales at examination (OR $0.22,95 \% \mathrm{Cl}=0.06$ to 0.83 , $P=0.03$ l

\section{Delay in secondary care}

The average delay in secondary care was 0.5 $+/-1.4$ days (median 0 days, range $0-12$ ). Eighty-two per cent of the patients were diagnosed with PE within 24 hours of arrival. In the following 48 hours another $12 \%$ were diagnosed. After multivariate analysis dyspnoea was associated with an early diagnosis $(\mathrm{OR} 0.35,95 \% \mathrm{Cl}=0.14$ to $0.90, P=0.03)$.

\section{DISCUSSION}

\section{Summary}

PE is regarded as a potentially fatal disorder, requiring timely diagnosis and treatment; however, the average time between symptom onset and diagnosis was almost 9 days. In this study, $23 \%$ of the patients were diagnosed with PE within a day of the onset of symptoms, whereas 23.8\% had symptoms for more than a week before diagnosis was made. The presence of chest pain led to an earlier diagnosis, as did the presence of calf pain.

The mean time between symptom onset and first consultation with a GP was 4.2 days. As far as the authors are aware, no studies have assessed the association between clinical variables and patient delay. This study found an association between the presence of chest pain and an early consultation. Because many patients are 


\section{Table 5. Patient delay: univariate analysis}

\begin{tabular}{|c|c|c|c|}
\hline \multirow[b]{2}{*}{ Variable } & \multicolumn{3}{|c|}{ Late presentation $\geq 6$ days } \\
\hline & Odds ratio & $95 \% \mathrm{Cl}$ & $P$-value \\
\hline Age $>65$ years & 1.06 & 0.57 to 2.00 & 0.85 \\
\hline Male sex & 1.23 & 0.66 to 2.30 & 0.52 \\
\hline Comorbidity & 1.34 & 0.69 to 2.58 & 0.39 \\
\hline \multicolumn{4}{|l|}{ Symptoms } \\
\hline Dyspnoea & 3.74 & 1.28 to 10.88 & $0.02^{\mathrm{a}}$ \\
\hline Chest pain & 0.45 & 0.24 to 0.85 & $0.01^{a}$ \\
\hline Cough & 1.71 & 0.89 to 3.28 & $0.11^{\mathrm{a}}$ \\
\hline Haemoptysis $^{\mathrm{b}}$ & - & - & - \\
\hline Fever & 0.46 & 0.16 to 1.37 & $0.16^{\mathrm{a}}$ \\
\hline Calf pain & 0.64 & 0.30 to 1.37 & 0.25 \\
\hline \multicolumn{4}{|l|}{ Signs } \\
\hline Tachycardiac $^{c}$ & 1.02 & 0.51 to 2.04 & 0.96 \\
\hline Signs of DVT & 0.68 & 0.31 to 1.51 & 0.35 \\
\hline \multicolumn{4}{|l|}{ Risk factors } \\
\hline Previous DVT/PE & 1.64 & 0.78 to 2.33 & $0.19^{a}$ \\
\hline Known malignancy & 0.92 & 0.33 to 2.54 & 0.87 \\
\hline Surgery or trauma ${ }^{d}$ & 0.65 & 0.22 to 2.20 & 0.45 \\
\hline Thrombophiliab & - & - & - \\
\hline
\end{tabular}

\section{Table 6. Delay in primary care: univariate analysis}

\begin{tabular}{|c|c|c|c|}
\hline \multirow[b]{2}{*}{ Variable } & \multicolumn{3}{|c|}{ Late referral $\geq 6$ days } \\
\hline & Odds ratio & $95 \% \mathrm{Cl}$ & $P$-value \\
\hline Age $>65$ years & 1.24 & 0.60 to 2.55 & 0.57 \\
\hline Male sex & 1.26 & 0.61 to 2.60 & 0.53 \\
\hline Comorbidity & 3.06 & 1.47 to 6.38 & $0.00^{\mathrm{a}}$ \\
\hline \multicolumn{4}{|l|}{ Symptoms } \\
\hline Dyspnoea & 2.34 & 0.79 to 6.94 & $0.13^{\mathrm{a}}$ \\
\hline Chest pain & 0.42 & 0.20 to 0.87 & $0.02^{\mathrm{a}}$ \\
\hline Cough & 2.06 & 0.98 to 4.29 & $0.06^{\mathrm{a}}$ \\
\hline Haemoptysis ${ }^{b}$ & - & - & - \\
\hline Fever & 0.73 & 0.24 to 2.21 & 0.58 \\
\hline Calf pain & 0.42 & 0.16 to 1.13 & $0.09^{a}$ \\
\hline \multicolumn{4}{|l|}{ Signs } \\
\hline Tachycardiac & 1.17 & 0.54 to 2.54 & 0.69 \\
\hline Rales & 0.43 & 0.12 to 1.46 & $0.18^{a}$ \\
\hline Decreased breath sounds & 1.24 & 0.40 to 3.25 & 0.71 \\
\hline Signs of DVT & 0.64 & 0.25 to 1.63 & 0.35 \\
\hline \multicolumn{4}{|l|}{ Risk factors } \\
\hline Previous DVT/PE & 0.94 & 0.37 to 2.42 & 0.90 \\
\hline Known malignancy & 0.75 & 0.21 to 2.62 & 0.65 \\
\hline Surgery or trauma ${ }^{d}$ & 0.21 & 0.03 to 1.57 & $0.13^{a}$ \\
\hline Thrombophiliab & - & - & - \\
\hline $\begin{array}{l}{ }^{a} P \leq 0.20 \text {, therefore data include } \\
\text { as heart rate }>100 \text { beats per } \\
P E=\text { pulmonary embolism. }\end{array}$ & $\begin{array}{l}\text { te logistic reg } \\
\text { or trauma i }\end{array}$ & $\begin{array}{l}{ }^{b} \text { No analysis du } \\
\text { veeks. DVT }=d e\end{array}$ & $\begin{array}{l}\text { c }{ }^{c} \text { Defined } \\
\text { mbosis. }\end{array}$ \\
\hline
\end{tabular}

aware that heart conditions can cause chest pain, it can be a frightening symptom. This could be the reason why PE patients with chest pain present earlier compared with those without this symptom. There was a borderline association between the presence of dyspnoea and a longer patient delay. Possibly, the link between dyspnoea and life-threatening conditions such as PE is not made.

In primary care the average delay was 3.9 days, although $75 \%$ of patients were referred within 1 day. The remaining 25\% had an average delay of 15.7 days, which is significant. Although validated algorithms are available to guide the diagnostic process of PE in primary care, these models are not of much use when the presenting symptoms and signs do not raise suspicion of $\mathrm{PE}$. The non-specific symptoms of PE can easily be attributed to another disease. The association this current study found between comorbidity and late referral seems to support this hypothesis. When faced with a patient with dyspnoea or chest pain, GPs have to draw up a general diagnostic hypothesis based on probability. Given this, it is not that surprising that GPs attribute symptoms such as dyspnoea to underlying disorders with similar symptoms and high prevalence, such as asthma, chronic obstructive pulmonary disease, or heart failure. However, when patients with comorbidity present with new respiratory symptoms or with an unexplained worsening of existing symptoms, PE should be considered. Although dyspnoea is the most common symptom of $P E,{ }^{14}$ the authors found no association between dyspnoea and early referral to secondary care. On the other hand, the presence of chest pain was associated with an early referral. One explanation for this may be that GPs are more likely to be triggered by the so-called classic presentation of PE with pleuritic chest pain and haemoptysis than by dyspnoea, although this is speculative.

In secondary care, the diagnostic delay was relatively small (that is, less than a day). More than $80 \%$ of the patients in this study were diagnosed with PE within 24 hours of arrival in hospital. In the following 48 hours another $12 \%$ were diagnosed. This study did not investigate the reason for referral and its effect on delay. However, it is likely that when PE is suspected in primary care land is in fact the reason for referrall delay in secondary care will be small. The presence of dyspnoea in secondary care led to an earlier diagnosis. Due to the relatively high prevalence of PE in secondary care and the 
Table 7. Delay in secondary care: univariate analysis

\begin{tabular}{|c|c|c|c|}
\hline \multirow[b]{2}{*}{ Variable } & \multicolumn{3}{|c|}{ Late diagnosis $\geq 3$ days } \\
\hline & Odds ratio & $95 \% \mathrm{Cl}$ & $P$-value \\
\hline Age $>65$ years & 0.84 & 0.33 to 2.13 & 0.71 \\
\hline Male sex & 0.68 & 0.27 to 1.71 & 0.41 \\
\hline Comorbidity & 1.28 & 0.49 to 3.33 & 0.61 \\
\hline \multicolumn{4}{|l|}{ Symptoms } \\
\hline Dyspnoea & 0.31 & 0.12 to 0.78 & $0.01^{a}$ \\
\hline Chest pain & 0.66 & 0.27 to 1.64 & 0.37 \\
\hline Cough & 0.83 & 0.34 to 2.49 & 0.88 \\
\hline Haemoptysis & 1.65 & 0.20 to 13.90 & 0.64 \\
\hline Fever & 1.88 & 0.65 to 5.47 & 0.25 \\
\hline Calf pain & 0.43 & 0.12 to 1.50 & $0.18^{a}$ \\
\hline \multicolumn{4}{|l|}{ Signs } \\
\hline Tachycardiac & 1.02 & 0.38 to 2.76 & 0.97 \\
\hline Rales & 0.84 & 0.24 to 3.00 & 0.79 \\
\hline Decreased breath sounds & 0.50 & 0.06 to 2.14 & 0.50 \\
\hline Signs of DVT & 1.04 & 0.36 to 2.97 & 0.95 \\
\hline \multicolumn{4}{|l|}{ Risk factors } \\
\hline Previous DVT/PE & 0.22 & 0.03 to 2.03 & $0.15^{\mathrm{a}}$ \\
\hline Known malignancy & 0.89 & 0.20 to 4.01 & 0.87 \\
\hline Surgery or trauma ${ }^{d}$ & 0.85 & 0.19 to 3.86 & 0.84 \\
\hline Thrombophiliab & - & - & - \\
\hline \multicolumn{4}{|c|}{$\begin{array}{l}{ }^{a} P \leq 0.20 \text {, therefore data included in multivariate logistic regression analysis. }{ }^{b} \text { No analysis due to lack of } \\
{ }^{c} \text { Tachycardia defined as heart rate }>100 \text { beats per minute. }{ }^{d} \text { Surgery or trauma in the previous } 4 \text { weeks. } \\
D V T=\text { deep venous thrombosis. } P E=\text { pulmonary embolism. }\end{array}$} \\
\hline
\end{tabular}

\section{Funding}

Not applicable

\section{Ethical approval}

Not applicable.

\section{Provenance}

Freely submitted; externally peer reviewed.

\section{Competing interests}

Jan WK van den Berg has acted as a paid speaker for GSK, AstraZeneca, Pfizer, and Chiesi. All other authors declare no competing interests.

\section{Discuss this article}

Contribute and read comments about this article: bjgp.org/letters more specific knowledge of the disorder, dyspnoea of unknown cause may be more often attributed to PE.

\section{Strengths and limitations}

To the authors' knowledge this is the first study to document the different stages of diagnostic delay of PE. As this study was conducted retrospectively the authors acknowledge some limitations. First, all patients included were diagnosed with PE. This excluded patients who did not seek medical care or patients in whom PE was not considered (bias against atypical cases). Another limitation of the study involves the recollection of the patient. Although the majority of patients were diagnosed within a could have had more trouble recollecting the exact time of symptom onset. When the period of delay was not described in days but in weeks or months an estimate of the amount of days was made, leading to a certain amount of imprecision. Also, it is impossible to know whether symptoms experienced by the patient were in fact a consequence of $\mathrm{PE}$ or whether another, couple of days, patients with a longer delay irrelevant, factor contributed. Another limitation of the study concerns the method used to obtain the data. The authors did not gather information directly from the patient, but used the doctor's account of patient recollection as written in the records. Furthermore, secondary care records were used and primary care records were obtained only when information was incomplete. Although the authors do not expect symptoms to have changed much between first presentation in primary care and later presentation in hospital, they cannot be sure. A more robust approach would have been to obtain all primary care records for comparison with secondary care records. Finally, only patients who were referred from primary care were included in this study. Baseline characteristics and described symptoms only reflect this group of patients and not all patients with PE.

\section{Comparison with existing literature}

This study found that the average time between symptom onset and diagnosis was almost 9 days. This delay is similar to that described by Bulbul et al ${ }^{4}$ ( 8.4 days) and almost twice as long as the delay reported by Elliott et al ${ }^{5}$ ( 4.8 days). The presence of chest pain led to an earlier diagnosis, as did the presence of calf pain. These associations have not been found in previous studies. ${ }^{4,6}$ The mean time between symptom onset and first consultation with a GP was 4.2 days. In comparison, research from the US by Elliott et a ${ }^{5}$ reported a patient delay of 2.9 days. As far as the authors know, no studies have assessed the association between clinical variables and patient delay. The current study found an association between the presence of chest pain and an early consultation.

\section{Implications for research and practice}

The primary goal was to document the diagnostic delay of $\mathrm{PE}$ in patients referred from primary care. With an average time of almost 9 days the results showed that the diagnostic delay of pulmonary embolism is substantial and that there is still room to reduce this delay, especially in primary care. More research is needed to identify factors in primary care that raise suspicion of PE or factors that give GPs a false sense of comfort. With this information better diagnostic models can be developed to guide the decision making around PE. Furthermore, both primary and secondary care physicians can help to reduce delays by educating patients about the symptoms and signs of $\mathrm{PE}$, especially patients with a high risk of developing the disorder. 


\section{REFERENCES}

1. Perrier A, Roy PM, Aujesky D, et al. Diagnosing pulmonary embolism in outpatients with clinical assessment, D-dimer measurement, venous ultrasound, and helical computed tomography: a multicenter management study. Am J Med 2004; 116(5): 291-299.

2. Nijkeuter M, Söhne M, Tick LW, et al. The natural course of hemodynamically stable pulmonary embolism: clinical outcome and risk factors in a large prospective cohort study. Chest 2007; 131(2): 517-523.

3. van Strijen MJ, de Monye W, Schiereck J, et al. Single-detector helical computed tomography as the primary diagnostic test in suspected pulmonary embolism: a multicenter clinical management study of 510 patients. Ann Intern Med 2003; 138(4): 307-314.

4. Bulbul Y, Ozsu S, Kosucu P, et al. Time delay between onset of symptoms and diagnosis in pulmonary thromboembolism. Respiration 2009; 78(1): 36-41.

5. Elliott CG, Goldhaber SZ, Jensen RL. Delays in diagnosis of deep vein thrombosis and pulmonary embolism. Chest 2005; 128(5): 3372-3376.

6. Ageno W, Agnelli G, Imberti D, et al. Factors associated with the timing of diagnosis of venous thromboembolism: results from the MASTER registry. Thromb Res 2008; 121(6): 751-756.

7. Andersen BA, Cacioppo JT. Delay in seeking a cancer diagnosis: delay stages and psychophysiological comparison processes. Br J Soc Psych 1995; 34(Pt 1): 33-52.
8. Walter F, Webster A, Scott S, Emery J. The Andersen model of total patient delay: a systematic review of its application in cancer diagnosis. J Health Serv Res Policy 2012; 17(2): 110-118.

9. Olesen F, Hansen RP, Vedsted P. Delay in diagnosis: the experience in Denmark. Br J Cancer 2009; 101: S5-S8. D0I:10.1038/sj.bjc.6605383.

10. Weller $D$, Vedsted $P$, Rubin $G$, et al. The Aarhus statement: improving design and reporting of studies on early cancer diagnosis. Br J Cancer 2012; 106(7): 1262-1267. DOI:10.1038/bjc.2012.68.

11. Geersing GJ, Erkens PM, Lucassen WA, et al. Safe exclusion of pulmonary embolism using the Wells rule and qualitative D-dimer testing in primary care: prospective cohort study. BMJ 2012; 345: e6564. DOI:10.1136/bmj.e6564.

12. Barais M, Morio N, Cuzon Beton A, et al. 'I can't find anything wrong: It must be a pulmonary embolism': diagnosing suspected pulmonary embolism in primary care, a qualitative study. PloS One 2014; 9(5): e98112. DOI:10.1371/ journal.pone.0098112.

13. Schiff GD, Hasan O, Kim S, et al. Diagnostic error in medicine: analysis of 583 physician-reported errors. Arch Intern Med 2009; 169(20): 1881-1887.

14. Stein PD, Beemath $A$, Matta F, et al. Clinical characteristics of patients with acute pulmonary embolism: data from PIOPED II. Am J Med 2007; 120(10): 871-879 